\title{
Nutritional and Functional Characteristics of Protein-Fortified Pasta from Sweet Potato
}

\author{
Jyothi Gopalakrishnan, Renjusha Menon, Gourikutty Padmaja, \\ Moothandassery Sankarankutty Sajeev, Subramoney Narayana Moorthy
}

Division of Crop Utilization, Central Tuber Crops Research Institute, Kerala, India.

Email: padmajabn@yahoo.com

Received June $9^{\text {th }}, 2011$; revised September $26^{\text {th }}, 2011$; accepted October $4^{\text {th }}, 2011$.

\begin{abstract}
Despite being a healthy low glycaemic index food, the production and consumption of sweet potatoes are decreasing globally. The global production trends indicated a decline from 130.47 million tonnes (MT) in 2004 to 107.64 MT in 2009, while the production in China, having the largest share towards world production of sweet potatoes, witnessed a decrease from 105.84 MT in 2004 to 81.21 MT in 2009. There is an interest in increasing consumption of healthy low glycaeimic index foods, especially in the context of a projected alarming rise in the diabetic population in the developing world by 2025. The objective of this study was to enhance the utilization of sweet potato as a low glycaemic food, mainly through its use in the development of high protein pasta. Among three protein sources, whey protein concentrate $(W P C)$, defatted soy flour (DSF), and fish powder (FP), WPC gave high quality pasta with strong starch-protein network formation, as evidenced from scanning electron microscopic studies and low in vitro starch digestibility. Protein nutritional quality was also high for WPC-fortified sweet potato pasta, with very high scores for lysine and leucine as well as high essential amino acid index and calculated protein efficiency ratio. Fractionation of starch showed that the WPC-fortified sweet potato pasta had the lowest rapidly digested starch (RDS) and the highest resistant starch (RS) content, indicating its potential as a low glycaemic food.
\end{abstract}

Keywords: Sweet Potato, Pasta, Protein, Fortification, Quality, Evaluation

\section{Introduction}

Sweet potato [Ipomoea batatas (L) Lam.] has assumed great significance in recent years as a health food due to the various bioactive principles in the roots. Nevertheless, the production statistics of sweet potato during 20042009 indicate a drastic reduction in the world production from 130.47 million tonnes (MT) in 2004 to 100.93 (MT) in 2007, followed by a small rise of 107.64 MT in 2009 [1]. China, which contributes the major share of world sweet potato production, also indicates a decline from 105.84 MT in 2004 to 81.21 MT in 2009 [1]. The total production of sweet potato roots in India also decreased from 1.18 MT to 1.12 MT during 2004-2007, indicating that its importance as a food item is decreasing. Despite being a carbohydrate rich food, sweet potato is also reported to have low glycaemic index $(<55)$, suggesting its suitability as a food for diabetic people [2]. Whilst the global prevalence of diabetes is projected to increase from $4 \%$ in 1995 to $5.4 \%$ by 2025 , approximately $170 \%$ increase in diabetic population has been predicted in developing countries, with India topping the list, followed by China [3]. FAO-WHO Expert Consultation recommends the increased consumption of low glycaemic foods rich in resistant starch, non-starch polysaccharides and oligosaccharides [4]. Foods with low glycaemic response are reported to be of use in the treatment of obesity, type 2 diabetes mellitus and in weight management [5]. Sweet potato is reported to have anti-diabetic property and the components contributing to this effect have been isolated and studied from white-skinned sweet potatoes [6]. The objective of this study was to enhance the utilization prospects of sweet potato through the development of a value added low glycaemic food like pasta.

Pasta, with its origin in Italy has gained wide popularity as a convenient and nutritionally palatable, low glycaemic food [7]. Although, traditionally pasta is made from durum wheat semolina which imparts the desired texture and cooking quality to the product, wheat semolina proteins are deficient in lysine and threonine leading to low biological value for the product [8]. Fortification 
of pasta with various protein sources such as legume flours, cheese, soy proteins, mustard protein isolate and gluten meal has been attempted by several workers, with a view to enhancing the nutritional value of pasta $[9,10]$. The possibility of using sweet potato for noodle and pasta manufacture has also been explored by different researchers $[11,12]$. As protein content and gluten strength are critical factors deciding the cooking quality of pasta and since sweet potato lacks gluten, fortification with protein sources like whey protein concentrate (WPC), defatted soy flour (DSF) and fish powder (FP) was attempted in the present study to understand their impact on starchprotein network formation. The three protein sources chosen for the study have been reported to have health promoting functional ingredients like immunoglobulin and lactoferrin (WPC), isoflavones (soy flour) and omega-3fatty acids (fish) $[13,14]$. The study aimed at the development of a slowly digestible functional pasta from sweet potato, which also has high protein content. Despite its cultivation in many states of India, there are no processed products having commercial potential and this has prompted the study.

\section{Materials and Methods}

\subsection{Samples}

Pale cream fleshed, white-skinned sweet potato variety viz., Sree Arun, grown at CTCRI Farm, was used for the study. Roots harvested at 105 days after planting were cleaned free of dirt, and healthy, undamaged roots were selected for the preparation of edible grade flour. Refined wheat flour (RWF) was purchased from the local market. Whey Protein Concentrate (WPC; Procon 3700) with crude protein and fat contents of $70.0 \%$ and $4.32 \%$ respectively was purchased from M/s Mahaan Proteins Ltd. Uttar Pradesh, India. Defatted soy flour (Vigorsoy) (DSF) having crude protein and fat contents of $53.0 \%$ and $0.6 \%$ respectively was purchased from the local market. Edible grade fish powder (crude protein and fat content of $75 \%$ and $14 \%$ respectively) was made by drying the cleaned fish (Indian anchovy; Stolephorus indicus) for $18 \mathrm{~h}$ under sun light, powdering and sieving through a 355 micron mesh size sieve. Gelatinized cassava (Manihot esculenta Crantz) starch (3.0\%) was used as a binder in the pasta formulations. Based on the optimization studies using $1.0 \%, 3.0 \%$ and $5.0 \%$ cassava starch, $3.0 \%$ cassava starch was used as binder for the pasta, as the water requirement of the pasta mix was low coupled with good cooking quality for this level.

\subsection{Preparation of Edible Grade Sweet Potato Flour}

Sweet potato roots were peeled and sliced to round discs of $C a .0 .5 \mathrm{~cm}$ thickness. The slices were soaked in acetic acid $(1.0 \% \mathrm{w} / \mathrm{v} ; 1.0 \mathrm{~kg}$ sweet potato slices per $5.0 \mathrm{~L}$ water) for $1 \mathrm{~h}$ to eliminate the browning problem, after which they were washed in running water and dried in the sun light for $36 \mathrm{~h}$. Dried chips were powdered in a blender and sieved (mesh: 355 micron) to obtain fine sweet potato flour (SPF).

\subsection{Pasta Formulations}

Treatment details for the various combinations are given in Table 1. All the formulations had 3\% cassava starch (w/w basis) which was gelatinized with distilled water $(100 \mathrm{ml})$ and added to the rest of the dry mix for each treatment. Starch was gelatinized by double plate method at $100^{\circ} \mathrm{C}$ for $15 \mathrm{~min}$.

\subsection{Preparation of Pasta}

Requisite quantity of water (standardized through repeated trials to get the smooth outer finish) was added to the mix from each treatment and uniformly kneaded in the Mixing Chamber of Italian Pasta making machine (P3 Model from M/s La Monferrina, Italy). Pasta was extruded at room temperature $\left(30^{\circ} \mathrm{C} \pm 1{ }^{\circ} \mathrm{C}\right)$ using the round die (No. 62) and cut to short pieces of length $3.0 \mathrm{~cm}$. The freshly extruded pasta tubes had an internal diameter of Ca. $0.5 \mathrm{~cm}$ and were dried at $50^{\circ} \mathrm{C}$ in an air oven for $18 \mathrm{~h}$ to get a product with $<12.0 \%$ moisture content.

\subsection{Hydration Level}

Water requirement for each pasta mix was quantified, as it was important to obtain pasta with smooth outer finish and non-breakable nature. Hydration level (\%) was calculated as water added $(\mathrm{ml}) \times 100 /$ weight of pasta mix $(\mathrm{g})$ [15].

\subsection{Cooking Procedure}

Pasta samples were dried to constant weight at $105^{\circ} \mathrm{C}$ for

Table 1. Formulations for protein fortified sweet potato pasta.

\begin{tabular}{cc}
\hline Treatments $^{\mathrm{a}}$ & Combinations \\
\hline $\mathrm{C}$ & $70 \% \mathrm{SPF}$ \\
$\mathrm{T} 1$ & $60 \% \mathrm{SPF}+10 \% \mathrm{WPC}$ \\
$\mathrm{T} 2$ & $50 \% \mathrm{SPF}+20 \% \mathrm{WPC}$ \\
$\mathrm{T} 3$ & $60 \% \mathrm{SPF}+10 \% \mathrm{DSF}$ \\
$\mathrm{T} 4$ & $50 \% \mathrm{SPF}+20 \% \mathrm{DSF}$ \\
$\mathrm{T} 5$ & $60 \% \mathrm{SPF}+10 \% \mathrm{FP}$ \\
$\mathrm{T} 6$ & $50 \% \mathrm{SPF}+20 \% \mathrm{FP}$ \\
\hline
\end{tabular}

${ }^{\mathrm{a} A l l}$ the formulations had $27 \%$ refined wheat flour (RWF) and $3 \%$ gelatinized cassava starch. 
2 - 3 h. Fifty gram of dry pasta was added to $500 \mathrm{ml}$ boiling water containing $1.0 \mathrm{~g}$ sodium chloride. Optimum cooking time (OCT) for each sample (al dente point) was determined using the Approved Method 66 - 50 [16], and corresponded to the time of disappearance of the white central part of the pasta. After the specific OCT for each sample, the cooked pasta was drained and surface water removed by keeping over a thin muslin cloth.

Swelling Index (SI) of cooked pasta ( $\mathrm{g}$ water absorbed per $\mathrm{g}$ of dry pasta) was determined as (weight of cooked pasta-weight of dry pasta)/weight of dry pasta [17]. Cooking loss (\%) was determined by drying the water drained from cooked pasta at $105^{\circ} \mathrm{C}$ and expressing the weight of residue as percentage of original pasta sample [18].

\subsection{Protein Nutritional Quality}

The crude protein content of cooked pasta samples was determined by the Kjeldahl method [19]. A modified method of Bidingmeyer et al. [20] was used for determining the amino acid profile of pasta samples. Amino acid analysis was done (in duplicate) only on $10 \%$ protein fortified pasta and compared with the control pasta. Samples $(100 \mathrm{mg})$ were hydrolyzed with $10.0 \mathrm{ml}$ of 6.0 $\mathrm{N} \mathrm{HCl}$ in sealed tubes (under $\mathrm{N}_{2}$ gas) for $24 \mathrm{~h}$ at $110^{\circ} \mathrm{C}$. The hydrolysates were flash evaporated for complete removal of acid and the volume was made up to $5.0 \mathrm{ml}$ using $0.05 \mathrm{~N} \mathrm{HCl}$. Amino acids in the hydrolysates were derivatised using phenyl isothiocyanate and the phenylthiocarbamyl amino acids were analysed using waters PicoTag amino acid analysis system, with waters 2487 Dual $\lambda$ absorbance detector and Pico-Tag column $(15.0 \mathrm{~cm}$ length and $3.5 \mathrm{~cm} \mathrm{dia).} \mathrm{Tryptophan} \mathrm{was} \mathrm{estimated} \mathrm{by} \mathrm{the} \mathrm{ninhydrin}$ method of Szakács and Perl [21].

Essential amino acid (EAA) score was calculated using the formula [22]

$$
\begin{aligned}
& \frac{\mathrm{g} \text { EAA in test sample }}{\mathrm{g} \text { total EAA in test sample }} \\
& \times \frac{\mathrm{g} \text { EAA in whole sample }}{\mathrm{g} \mathrm{EAA} \text { in egg }} \times 100
\end{aligned}
$$

Essential amino acid index (EAAI\%) was calculated as per the formula of Oser [23] from the ratio of the total EAA in test sample to the total EAA in whole egg protein and expressed as percentage. Biological value (BV) was calculated using the formula of Oser [24] as:

$$
\mathrm{BV}=1.09 \times \operatorname{EAAI}(\%)-11.7
$$

Nutritional index (NI) was calculated using the formula of Crisan and Sands [25] as:

$$
\mathrm{NI}=\frac{\operatorname{EAAI}(\%) \times \operatorname{Protein}(\%)}{100}
$$

Computed protein efficiency ratio (C-PER) was calculated according to the formula of Satterlee et al. [26] as:

$$
\begin{aligned}
\mathrm{C}-\mathrm{PER}= & -2.1074 \times 7.1312(\mathrm{SPCR}) \\
& -2.5185 \times(\mathrm{SPCR})^{2}
\end{aligned}
$$

where SPCR is the ratio the total EAA score for test sample to total EAA score for casein.

Nitrogen solubility index (NSI) was determined by the method of Obulesu and Bhagya [27]. One gram dry pasta flour was suspended in $20.0 \mathrm{ml}$ distilled water and after adjusting the $\mathrm{pH}$ to 7.0 , the suspension was shaken for 1 $\mathrm{h}$ using a rotary shaker at room temperature. The clear supernatant obtained by centrifugation at $8000 \mathrm{rpm}$ for $10 \mathrm{~min}$, was used to determine soluble nitrogen by Kjeldahl method [19]. Values are expressed as percentage of total $\mathrm{N}$ in the material.

In vitro protein digestibility was determined by the procedure of AOAC [19] with slight modifications. Dried pasta powder $(100 \mathrm{mg})$ was suspended in $10.0 \mathrm{ml}$ distilled water and allowed to hydrate for $1 \mathrm{~h}$. The $\mathrm{pH}$ of the sample was adjusted to 8.0 and equilibrated for 30 min at $37^{\circ} \mathrm{C}$. One tablet of Panzynorm-N (manufactured by M/s German Remedies India, Ltd., Mumbai, India) containing 10,000 units of lipase, 9000 units of alphaamylase and 500 units of protease, was dissolved in 5.0 $\mathrm{ml}$ sodium phosphate buffer $(0.1 \mathrm{M}$; $\mathrm{pH} 8.0)$. One milliliter of the digestive enzyme was added and incubated at $37^{\circ} \mathrm{C}$ for $1 \mathrm{~h}$. Enzyme and sample blanks were also simultaneously kept and after the reaction period, the enzyme was heat killed and the total amino acid content in the supernatant was quantified using ninhydrin reagent [28]. In vitro protein digestibility is expressed as $\mathrm{mg}$ amino groups (Leucine equivalent) released per h per 100 g cooked pasta (dwb).

\subsection{In Vitro Starch Digestibility}

Total starch content in the cooked pasta samples was determined by the titrimetric method of Moorthy and Padmaja [29]. In vitro starch digestibility (IVSD) of cooked pasta samples was determined as per the procedures of Englyst et al. [30], McCleary and Monaghan [31] and Kim et al. [32] with slight modifications. Pasta samples were cooked as described above and after surface drying on filter paper (Whatman No. 1), they were cut into small pieces of $C a$. $1.0 \mathrm{~mm}$ length. Five grams (3 replicates) sample were mixed with $\mathrm{HCl}-\mathrm{KCl}$ buffer $(\mathrm{pH}$ $1.5,10.0 \mathrm{ml}$ ) and equilibrated at $37^{\circ} \mathrm{C}$ for $10 \mathrm{~min}$. Pepsin (SIGMA, USA) was added to initiate proteolysis $(0.4 \mathrm{ml}$ from $10.0 \mathrm{ml} \mathrm{HCl}-\mathrm{KCl}$ buffer containing $1.0 \mathrm{~g}$ pepsin). 
Samples were incubated at $37^{\circ} \mathrm{C}$ for $1 \mathrm{~h}$, after which 40.0 $\mathrm{ml}$ sodium phosphate buffer $(0.02 \mathrm{M}$; $\mathrm{pH} 6.9$ containing $0.12 \mathrm{M}$ sodium chloride) was added. After equilibrating for $10 \mathrm{~min}$ at $37^{\circ} \mathrm{C}, 1.0 \mathrm{ml}$ Panzynorm N (one tablet dissolved in $5.0 \mathrm{ml} 0.02 \mathrm{M}$ sodium phosphate buffer $\mathrm{pH}$ 6.9) was added and incubation continued for $20 \mathrm{~min}$. One milliliter of the supernatant was withdrawn and heat inactivated at $100^{\circ} \mathrm{C}$. The aliquot was added to $3.0 \mathrm{ml}$ sodium acetate buffer $(0.2 \mathrm{M}$; $\mathrm{pH} 4.8)$ and incubated at $60^{\circ} \mathrm{C}$ for a further $10 \mathrm{~min}$ with $0.25 \mathrm{ml}$ Dextrozyme GA (M/s Novo Industries, Denmark). Incubation of the Panzynorm assay system was continued up to $120 \mathrm{~min}$ and aliquots of $1.0 \mathrm{ml}$ were withdrawn at every $20 \mathrm{~min}$ interval. Samples were treated identically with $0.25 \mathrm{ml}$ Dextrozyme GA. Glucose content in each aliquot was quantified using Glucose oxidase (EC 1.1.3.4)—peroxidase (EC 1.11.1.7) reagent (M/s Beacon Diagnostics Pvt. Ltd. Gu- jarat, India). Starch measured at 20 min [Glucose expressed as $(\mathrm{g} / 100 \mathrm{~g}$ pasta $) \times 0.9$ ] was taken as the rapidly digested starch (RDS) and that measured at $120 \mathrm{~min}$. was taken as RDS + slowly digested starch (SDS) [32] Resistant starch (RS; starch remaining undigested after 120 min.) was computed as the difference between total starch content in the cooked pasta $(\mathrm{g} / 100 \mathrm{~g} \mathrm{dwb})$ and $(\mathrm{RDS}+\mathrm{SDS})_{120 \mathrm{~min}}$. Separate enzyme and substrate blanks were maintained for each sample.

\subsection{Scanning Electron Microscopy (SEM)}

Scanning Electron Microscopy gives information about the size, shape and arrangement of particles in the pasta matrix [33]. Cooked pasta (as per the method described earlier), immediately after cooking was surface dried by blotting the adherent water on a filter paper (Whatman No. 1) was transversely cut using a razor blade and the sample was mounted onto brass stubs using double-sided carbon conductive adhesive tape. A gold coating (10 - 15 $\mathrm{mm}$ thick) was then applied using JEOL JFC 1600 magnotron sputtering unit with $10 \mathrm{~mA}$ current for 80 seconds. Bulk samples were examined at $10 \mathrm{kV}$ and $1 \mathrm{~Pa}$ vacuum using a JEOL JSM6390 LV scanning electron microscope (Oxford, UK).

\section{Results and Discussion}

Sweet potato is being increasingly realized as a health food due to its anti-oxidant, anti-diabetic and low glycaemic properties. Since sweet potato lacks gluten type proteins, incorporation of appropriate protein additives was necessary to maintain the quality of sweet potato pasta which also helped in augmenting the protein nutritional quality of pasta. With a view to enhancing the utilization of sweet potato, an easy to cook nutritionally fortified, low glycaemic pasta was developed from sweet potato flour using protein sources like whey protein con- centrate (WPC), defatted soy flour (DSF) and fish powder (FP) and the nutritional, cooking as well as digestibility characteristics were studied.

\subsection{Cooking Characteristics}

\subsubsection{Hydration Level}

The control pasta made with $70 \%$ sweet potato flour had the highest hydration level (HL; 50\%) indicative of the high water holding capacity of the flour. Among the three protein sources, HL (\%) was the highest for WPC-fortified pasta (40\%) (Table 2). Traditional pasta from durum wheat semolina has been reported to require $25 \%-34 \%$ water and dough containing non-traditional ingredients requires more water to attain proper consistency and non-breakable nature [15]. During pasta making, starch and proteins undergo structural changes and the wheat proteins are responsible for the absorption of water during mixing and cooking, imparting the compact texture to durum semolina pasta [7]. Water requirement for each pasta mix may be different depending on the type of ingredients. In our study, we have used 3\% gelatinized cassava starch as a binder for the pasta and hence a strong dough was obtained that could be uniformly extruded at around $35^{\circ} \mathrm{C}-37^{\circ} \mathrm{C}$. Tam et al. [34] reported the use of pre-gelatinized maize starch as a binder in the preparation of Bihon-type noodles from maize starch. As the temperature during mixing was below $40^{\circ} \mathrm{C}$ in our study, there may not be any structural changes induced in sweet potato starch. Vansteelandt and Delcour [35] also observed that structural changes in wheat starch do not occur at the mixing stage except the absorption of water. Lowest hydration level (\%) was obtained for FP-fortified pasta mix and we used fish powder having a fat content of $C a .14 \%$. Ingredients with higher levels of lipid are reported to lower the water requirement during pasta making [15].

Table 2. Hydration level, cooking loss and swelling index of high protein pasta from sweet potato.

\begin{tabular}{cccc}
\hline Treatments $^{\mathrm{a}}$ & $\begin{array}{c}\text { Hydration level } \\
(\%)\end{array}$ & $\begin{array}{c}\text { Cooking loss } \\
(\%)\end{array}$ & $\begin{array}{c}\text { Swelling Index } \\
(\mathrm{SI})\end{array}$ \\
\hline Control & 50 & $12.86 \pm 0.12$ & $1.43 \pm 0.01$ \\
T1 & 40 & $11.45 \pm 0.75$ & $1.47 \pm 0.15$ \\
T2 & 40 & $12.06 \pm 0.12$ & $1.40 \pm 0.06$ \\
T3 & 30 & $10.90 \pm 0.12$ & $1.56 \pm 0.05$ \\
T4 & 36 & $13.40 \pm 0.69$ & $1.60 \pm 0.03$ \\
T5 & 26 & $13.90 \pm 0.46$ & $1.66 \pm 0.00$ \\
T6 & 26 & $16.06 \pm 0.00$ & $1.75 \pm 0.15$ \\
\hline
\end{tabular}

${ }^{a}$ All the formulations had $27 \%$ refined wheat flour (RWF) and 3\% gelatinized cassava starch; each value is Mean \pm S.D. 


\subsubsection{Cooking Loss}

The quantity of solids going into water during cooking of pasta is a determinant of pasta quality and compact textured pasta leads to lower cooking loss. We found that the optimal cooking time (OCT) determined as per the AACC method was 2 - 4 min for the various pastas (data not shown), which was much less than the reported values of 7 - 9 min for the traditional durum wheat pasta [10]. Cooking loss was quantified at the OCT and it was found that all the pasta samples had higher cooking loss (Table 2). Fish powder fortification led to higher cooking loss $(12 \%-16 \%)$ for the pasta, indicative of a weaker starch-protein interaction, which gets disrupted during cooking. Rayas-Duarte et al. [36] obtained higher cooking loss in spaghetti fortified with $30 \%$ buckwheat, amaranth or lupin flours and attributed this to the weaking of gluten. Limroongreungrat and Huang [12] found that pasta made from $100 \%$ alkali-treated sweet potato flour had the lowest cooking loss $(9.9 \%)$, while DSF fortification raised the cooking loss to $11 \%-16 \%$. Petitot et al. [10] also reported higher cooking loss in semolina pasta fortified with $35 \%$ split pea or faba bean flours, as compared to only $5.6 \%$ in durum wheat semolina pasta.

Higher cooking loss resulting from the dilution of gluten and weakening of starch-protein network was also reported in wheat spaghetti fortified with legume flours [36]. On the contrary, very low cooking loss of $1.6 \%$ $1.8 \%$ was only reported in corn starch based Bihon-type noodles, where the manufacturing process itself involves gelatinization of starch prior to drying [34], which indicates that starch gelatinization and adhesion can help reduce cooking loss. Malcolmson et al. [37] observed that cooking loss of optimally cooked spaghetti was influenced primarily by the protein level and entrapment of gelatinized starch in protein network could prevent the leaching of starch components.

\subsubsection{Swelling Index}

Swelling Index (SI) of pasta is an indicator of the water absorbed by the starch and proteins during cooking, which is utilized for the gelatinization of starch and hydration of proteins. Higher swelling index was obtained in our study for the pasta fortified with DSF and FP compared to the control pasta which had a SI of 1.43 (Table 2). Gelencsér et al. [5] reported SI values of 1.8 1.9 for pasta from two wheat varieties like Triticum aestivum and T. durum and found no differences during fortification with resistant starch. Tudorică et al. [33] reported SI values of 1.85 for durum semolina pasta, while higher values were obtained for fiber-fortified pasta. Spaghetti fortified with buckwheat, amaranth and lupin flours were reported to swell 2.9 - 3.0 times during cooking [36]. Non-wheat ingredients lead to discontinuity within the gluten matrix and result in weak dough properties [15]. During cooking of pasta, starch absorbs water and swells and the granular structure collapses leading to the leaching of amylose. Sweet potato pasta formulations used in our study had $27 \%$ refined wheat flour. However, addition of non-wheat ingredients like sweet potato flour and protein sources could have led to dilution of glutens. Nevertheless, the restricted swelling (low SI values) in the pasta products compared to the reported values of $1.8-1.9$ for durum semolina pasta indicates that the added proteins also may be competing with starch for water. Tudorică et al. [33] reported that the uneven distribution of water within the pasta matrix due to the competitive hydration of fiber, led to prevention of starch swelling and hence the increased cooking loss was due to the disruption of protein-starch network.

\subsection{Protein Nutritional Quality}

Although pasta is a rich source of carbohydrates, wheat proteins are low in essential amino acids such as lysine and threonine [8]. Legume flours rich in lysine have been used for pasta and spaghetti fortification $[15,36]$. We have produced high protein sweet potato pasta using three protein sources like whey protein concentrate (WPC), defatted soy flour (DSF) and fish powder (FP) each having specific functional attributes as well. The crude protein content could be significantly enhanced in the pasta, with highest values being obtained for WPC $(20 \%)$ and DSF (20\%) fortified pasta. The crude protein contents in the pasta were $5.14 \%$ (control), 9.41\% (T1), 16.44\% (T2), $9.85 \%$ (T3), $15.32 \%$ (T4), $10.29 \%$ (T5) and $12.84 \%$ (T6). The dry protein sources like WPC, DSF and FP (Indian anchovy) had crude protein contents of $70,53 \%$ and $75 \%$ respectively.

The detailed amino acid pattern of the control as well as $10 \%$ protein fortified pasta was only studied and the essential amino acids (EAA) were compared with the FAO reference pattern [38] for school going children (10 12 years) and adults who are the likely consumers and the pattern for wheat flour pasta. It was found that lysine enhancement was the major advantage obtained through fortification with WPC (5.30 g/100 g protein), DSF (4.58 $\mathrm{g} / 100 \mathrm{~g}$ protein $)$ and $\mathrm{FP}(4.05 \mathrm{~g} / 100 \mathrm{~g}$ protein $)$, while the wheat flour pasta had a reported value of only $2.01 \mathrm{~g} / 100$ $\mathrm{g}$ protein [39]. The control pasta had almost similar level $(1.91 \mathrm{~g} / 100 \mathrm{~g})$ of lysine only (Table 3). The lysine content in WPC-fortified pasta was much higher than the requirement for adults and children (1.60 and 4.40 respectively). Leucine and threonine were two other EAA that were high in the protein enriched pasta. Highest values of leucine (7.79 g/100 g protein) could be obtained in WPC-fortified pasta. Lysine enrichment $(2.8 \%$ - 
Table 3. Amino acid pattern (g/100 g protein) of protein enriched pasta from sweet potato.

\begin{tabular}{|c|c|c|c|c|c|c|c|}
\hline \multirow{3}{*}{ Amino acid } & \multicolumn{7}{|c|}{ Amino acid content } \\
\hline & \multirow{2}{*}{ Control } & \multirow{2}{*}{$\begin{array}{l}\text { WPC fortified } \\
\text { (T1) }\end{array}$} & \multirow{2}{*}{$\begin{array}{l}\text { DSF fortified } \\
\text { (T3) }\end{array}$} & \multirow{2}{*}{$\begin{array}{l}\text { FP fortified } \\
\text { (T5) }\end{array}$} & \multicolumn{2}{|c|}{ FAO/WHO/UNU reference pattern (1985) [38] } & \multirow{2}{*}{$\begin{array}{l}\text { Wheat flour } \\
\text { pasta }^{b}\end{array}$} \\
\hline & & & & & Children $10-12$ years & Adult & \\
\hline \multicolumn{8}{|l|}{ Essential } \\
\hline Ileu & 2.95 & 3.96 & 3.08 & 2.41 & 2.82 & 1.30 & 4.17 \\
\hline Leu & 5.01 & 7.79 & 5.75 & 4.78 & 4.40 & 1.90 & 7.65 \\
\hline Lys & 1.91 & 5.30 & 4.58 & 4.05 & 4.40 & 1.60 & 2.01 \\
\hline Met + Cys & 2.18 & 3.14 & 2.08 & 2.18 & 2.20 & 1.70 & 4.02 \\
\hline Phe + Tyr & 7.10 & 6.57 & 6.95 & 5.39 & 2.20 & 1.90 & 7.81 \\
\hline Thr & 4.10 & 4.95 & 4.13 & 4.52 & 2.80 & 0.90 & 2.88 \\
\hline Val & 3.47 & 4.40 & 3.86 & 3.11 & 2.50 & 1.30 & 4.99 \\
\hline Try & 0.72 & 0.77 & 0.79 & 0.74 & 0.90 & 0.50 & 0.96 \\
\hline \multicolumn{8}{|l|}{ Non-essential } \\
\hline Asp & 6.16 & 10.52 & 10.35 & 7.29 & & & 4.67 \\
\hline Glu & 16.24 & 21.22 & 21.19 & 13.45 & & & 32.22 \\
\hline Ser & 4.29 & 5.49 & 5.59 & 3.65 & & & 5.21 \\
\hline Gly & 3.39 & 2.63 & 3.43 & 7.26 & $\mathrm{NR}^{\mathrm{a}}$ & $\mathrm{NR}^{\mathrm{a}}$ & 3.25 \\
\hline His & 2.27 & 2.21 & 2.40 & 2.53 & & & 2.07 \\
\hline Arg & 4.30 & 3.54 & 5.80 & 13.83 & & & 3.62 \\
\hline Ala & 2.94 & 3.66 & 3.47 & 4.75 & & & 3.29 \\
\hline Pro & 6.82 & 6.22 & 5.41 & 3.69 & & & 10.91 \\
\hline
\end{tabular}

${ }^{\mathrm{a}}$ NR- Nothing reported; ${ }^{\mathrm{b}}[39]$ in the Reference Section.

4.3\%) was reported in spaghetti fortified with buck wheat, amaranth and lupin flours [36]. We found that the level of lysine enhancement that could be achieved through protein fortification in sweet potato pasta was highly significant. Aspartic acid levels were higher in the protein-enriched pasta than wheat flour pasta, while two nonessential amino acids, Arginine and glycine were very high in FP-fortified pasta (Table 3).

Essential amino acid scores (EAA score) for proteinenriched pastas from sweet potato show very high values for Thr $>$ Leu $>$ Lys $>$ Ileu for WPC-pasta, Thr $>$ Phe + Tyr $>$ Leu $>$ Lys for DSF-pasta and Thr $>$ Phe + Tyr $>$ Lys $>$ Leu for FP-pasta (Table 4). Whilst lysine was the first limiting amino acid (LAA) for control pasta, it was not a LAA for the three protein fortified pastas. Tryptophan was the first LAA for WPC-pasta, while it was the second LAA for the other two protein-enriched pastas. Threonine, reported as the $2^{\text {nd }}$ limiting amino acid for wheat pasta [8], had the highest score for all the three protein fortified pasta. There are no reports on the detailed amino acid scoring pattern for durum wheat pasta or any of the several protein-fortified pasta, except for the total protein or lysine content [36]. The essential amino acid composition of defatted soy flour has been studied by Obulesu and Bhagya [27], who found that Met + Cys was less ( $1.8 \mathrm{~g} / 100 \mathrm{~g}$ protein), while Phe $+\mathrm{Tyr}(8.0$ $\mathrm{g} / 100 \mathrm{~g}$ protein) was higher than the FAO reference pattern. Essential amino acid score of WPC-80 (with $80 \%$ protein) was studied by Sindayikengera and Xia [40], who found that Val, Phe + Tyr and Ileu were the $1^{\text {st }}$, $2^{\text {nd }}$ and $3^{\text {rd }}$ LAA respectively. Highest scores were reported for Met + Cys, Lys and Thr. We found that the WPC fortified pasta had Met + Cys as the $2^{\text {nd }}$ LAA and the difference could have occurred from the WPC-70 (with $70 \%$ protein) used in our studies.

Protein nutritional indices like Essential amino acid index (EAAI), calculated biological value (BV), nutritional index (NI) and calculated protein efficiency ratio 
Table 4. Essential amino acid (EAA) score for protein enriched pasta from sweet potato.

\begin{tabular}{ccccc}
\hline \multirow{2}{*}{ EAA } & \multicolumn{4}{c}{ Essential amino acid score } \\
\cline { 2 - 5 } & $\mathrm{C}$ & $\mathrm{T} 1$ & $\mathrm{~T} 3$ & $\mathrm{~T} 5$ \\
\hline Ileu & 97.55 & 130.95 & 101.85 & 79.70 \\
Leu & 104.03 & 161.75 & 119.39 & 99.25 \\
Lys & 48.72 & 135.20 & 116.84 & 103.32 \\
M + C & 68.30 & 98.37 & 65.16 & 68.30 \\
P + T & 136.33 & 126.15 & 133.45 & 103.49 \\
Thr & 155.77 & 188.07 & 156.91 & 171.73 \\
Val & 93.88 & 119.05 & 104.44 & 84.14 \\
Try & 75.63 & 80.88 & 82.98 & 77.73 \\
$1^{\text {st }}$ LAA & Lys & Try & M + C & M + C \\
$2^{\text {nd }}$ LAA & M + C & M + C & Try & Try \\
$3^{\text {rd }}$ LAA & Try & Val & Ileu & Ileu \\
\hline
\end{tabular}

(C-PER) given in Table 5 are parameters to assess the protein nutritional quality of sweet potato pasta. The former two indices like EAAI and BV were much higher for WPC-pasta and DSF-pasta than the control SP-pasta. Highest BV (70.34) for WPC-pasta indicates the superior quality of the protein, which is also substantiated by the high EAAI (\%) of 75.27. Nutritional index (NI) and C-PER were also the highest for WPC-pasta. Fish powder fortified pasta had EAAI (\%) and BV similar to the control pasta. Nevertheless, the NI was much higher (9.32) than the control pasta (4.31), resulting from the high crude protein content in it. Sindayikengera and Xia [40] reported EAAI (\%), BV, NI and C-PER for WPC-80 as $72.28,67.09,58.42$ and 4.85 respectively and the high NI value corresponds to $80 \%$ protein in WPC- 80 . We had used only $10 \%$ WPC-70 for protein fortification in pasta and hence the difference in NI. Obulesu and Bhagya [37] also reported EAAI (\%), BV, NI and C-PER values of 76, 71, 42 and 1.6 respectively for defatted soy flour with a crude protein content of 55\%. Nutritional index values of 6.14 were obtained for the $10 \%$ DSF fortified pasta in our study, which had crude protein content of $55 \%$.

\subsubsection{Nitrogen Solubility Index}

The nitrogen solubility index (NSI) expressed as percentage of total nitrogen for the control as well as $10 \%$ protein-fortified pasta reduced significantly in the fortified samples (Table 5). Whilst the control pasta had NSI of $14.0 \%$, it decreased to $10.0 \%, 8.0 \%$ and $6.0 \%$ respectively for the WPC, DSF and FP-fortified pasta.
Table 5. In vitro protein digestibility and Nutritional indices of protein-fortified pasta from sweet potato.

\begin{tabular}{ccccc}
\hline Parameters & C & T1 & T3 & T5 \\
\hline EAAI (\%) & 56.00 & 75.27 & 63.71 & 55.47 \\
BV & 49.34 & 70.34 & 57.74 & 48.76 \\
NI & 4.31 & 11.59 & 6.14 & 9.32 \\
C-PER & 1.37 & 2.09 & 1.68 & 1.40 \\
IVPD & 479.96 & 496.64 & 488.48 & 491.72 \\
NSI (\%) & 14.00 & 10.00 & 8.00 & 6.00 \\
\hline
\end{tabular}

The decreased NSI resulted from the starch-protein interactions occurring during the pasta making processes. Such interactions could mask the polar side-chains of proteins, leading to less protein solubility. Obulesu and Bhagya [27] reported that the NSI of soy flour was 79\% and it reduced to $12 \%$ in soy protein isolate. Sindayikengera and Xia [40] also reported high solubility $(>80 \%)$ indices for WPC- 80 and sodium caseinate and enzymemediated hydrolysis further increased the solubility. The compact texture of the dry pasta resulting from proteinstarch interactions might have resulted in the low protein solubility in our study.

\subsubsection{In Vitro Protein Digestibility}

Although nitrogen solubility was reduced for the protein-fortified pasta, in vitro protein digestibility ( $\mathrm{mg}$ leucine equivalent $/ \mathrm{h} / 100 \mathrm{~g}$ dry pasta) was significantly high for the three $10 \%$ protein-fortified pasta as compared to the control pasta. There was no significant difference in IVPD between the three types of proteins (Table 5).

Proportionate increase in IVPD was reported with increase in the degree of hydrolysis of WPC- 80 and sodium caseinate [40]. Obulesu and Bhagya [27] also reported high protein digestibility for DSF and soy protein isolate.

\subsection{In Vitro Starch Digestibility (IVSD)}

Pasta is a widely popular carbohydrate diet, with a unique feature of progressive release of carbohydrates, leading to low postprandial glucose and insulin response. There are a large number of studies on the starch digestibility of traditional durum semolina pasta as well as that fortified with non-traditional ingredients [4,5,7]. We found that the sweet potato pasta (control and proteinfortified) also exhibited the "lente" (slow release) properties and glucose was released into the in vitro system in a progressive manner. The control SPF-pasta had the highest IVSD of 51.47 units at 120 min while least IVSD was observed for the WPC (10 and 20\%) fortified pasta (T1 and T2; Table 6). Among the three sources, DSF was the 
Table 6. Time course production of glucose during digestion of starch in sweet potato pasta.

\begin{tabular}{ccccccc}
\hline \multirow{2}{*}{ Treatments $^{\mathrm{a}}$} & \multicolumn{9}{c}{ Time (min) } \\
\cline { 2 - 7 } & 20 & 40 & 60 & 80 & 100 & 120 \\
\hline C & $44.93 \pm 2.40$ & $46.13 \pm 0.59$ & $47.25 \pm 0.66$ & $49.71 \pm 1.21$ & $51.19 \pm 1.78$ & $51.47 \pm 0.59$ \\
T1 & $37.80 \pm 1.35$ & $38.23 \pm 0.96$ & $38.64 \pm 0.00$ & $39.87 \pm 0.74$ & $43.23 \pm 1.27$ & $46.40 \pm 1.50$ \\
T2 & $42.80 \pm 0.82$ & $43.92 \pm 0.00$ & $44.47 \pm 1.06$ & $45.43 \pm 3.00$ & $48.03 \pm 1.33$ & $48.80 \pm 1.47$ \\
T3 & $46.67 \pm 2.83$ & $47.43 \pm 3.37$ & $49.80 \pm 4.19$ & $51.30 \pm 3.47$ & $53.74 \pm 0.00$ & $58.33 \pm 1.37$ \\
T4 & $51.43 \pm 3.00$ & $55.10 \pm 3.14$ & $56.56 \pm 0.00$ & $58.40 \pm 1.90$ & $58.63 \pm 3.07$ & $61.23 \pm 2.27$ \\
T5 & $45.20 \pm 2.39$ & $47.67 \pm 0.32$ & $48.57 \pm 0.70$ & $52.17 \pm 1.87$ & $52.87 \pm 2.91$ & $55.53 \pm 0.00$ \\
T6 & $48.17 \pm 1.51$ & $48.97 \pm 2.03$ & $49.10 \pm 1.90$ & $49.77 \pm 1.67$ & $55.77 \pm 2.16$ & $57.50 \pm 1.49$ \\
\hline
\end{tabular}

${ }^{\mathrm{a}} \mathrm{T} 1, \mathrm{~T} 3$ and $\mathrm{T} 5$ had $60 \%$ sweet potato flour, while T2, T4 and T6 had 50\% sweet potato flour; all the formulations had $27 \%$ refined wheat flour (RWF) and $3 \%$ gelatinized cassava starch; each value is Mean \pm S.D.

least effective in reducing the IVSD of SPF-pasta. Significantly lower starch digestibility was observed for T1 (10\% WPC fortification) which increased in the $20 \%$ WPC fortified pasta (T2). Sweet potato has been reported as a low glycaemic food with a glycaemic index (GI) of $<55$ [2].

Combining the low glycaemic property of sweet potato with the "lente" property of pasta, we have obtained pasta having low in vitro starch digestibility. Petitot et al. [7] observed that the enzymatic susceptibility of starch in pasta depends on the special organization and structural state of the components. The low degree of mastication and large particle size limiting the surface area over which amylase can act also contribute to the slow in vivo release of glucose [32].

The digested starch fractions such as rapidly digested starch (RDS; starch digested in the first 20 minutes of enzyme action), slowly digested starch (SDS; starch digested from $20 \mathrm{~min}$ to $120 \mathrm{~min}$ ) as well as the resistant starch (RS; starch remaining undigested after $120 \mathrm{~min}$. calculated as [Total starch (data not shown) - (RDS + SDS)] were quantified for the control as well as protein-fortified pasta. It was found that the RDS fraction was the highest for control SPF-pasta and the lowest for 10\% WPC-fortified pasta (Table 7; T1 and T2). Slowly digested starch was more in the T3 $(10 \% \mathrm{DSF})$ and T5 $(10 \% \mathrm{FP})$ treatments. Resistant starch fraction was the highest in $\mathrm{T} 1$ (17.08 g/100 g cooked pasta, dwb), followed by $\mathrm{T} 3$ and $\mathrm{T} 5$. Increasing the level of proteins from $10 \%$ to $20 \%$ increased starch digestibility and hence the RDS fractions were more and RS fractions less in the 20\% fortified samples (Table 7). This also corresponded with the IVSD data, where higher glucose levels were obtained for $20 \%$ protein fortified samples. Resistant starch showed significant difference between $10 \%$ and $20 \%$ fortification levels. Gelencsér et al. [41] studied the
Table 7. Rapidly digested, slowly digested and resistant starch fractions ( $\mathrm{g} / \mathbf{1 0 0} \mathrm{g}$ cooked pasta on dry basis) in the high protein pasta from sweet potato.

\begin{tabular}{cccc}
\hline Treatments $^{\mathrm{a}}$ & RDS & SDS & RS \\
\hline C & $40.44 \pm 2.43$ & $5.89 \pm 3.08$ & $12.67 \pm 1.41$ \\
T1 & $34.02 \pm 1.21$ & $7.74 \pm 0.99$ & $17.08 \pm 1.35$ \\
T2 & $38.52 \pm 0.74$ & $5.40 \pm 1.67$ & $11.51 \pm 1.33$ \\
T3 & $42.00 \pm 2.55$ & $10.50 \pm 3.18$ & $15.80 \pm 1.23$ \\
T4 & $46.29 \pm 2.70$ & $8.82 \pm 3.29$ & $9.72 \pm 2.04$ \\
T5 & $40.68 \pm 2.15$ & $9.30 \pm 2.15$ & $14.82 \pm 0.00$ \\
T6 & $43.35 \pm 1.36$ & $8.40 \pm 0.41$ & $8.05 \pm 1.34$ \\
\hline
\end{tabular}

${ }^{a}$ Treatment details as in Table 6; all the formulations had $27 \%$ refined wheat flour (RWF) and $3 \%$ gelatinized cassava starch; each value is Mean \pm S.D.

effect of two resistant starches on the digestibility of wheat pasta and reported that the additives were heat sensitive and hence produced insignificant effect on the starch digestibility. Protein-starch interactions affect the amylolysis of starch, thereby reducing the digestibility of pasta and WPC might be forming the strongest network, preventing the entry of alpha-amylase. Among the three protein sources, WPC fortification resulted in a stronger protein-starch network than the other two proteins, which could be evidenced from the higher levels of RDS and lower levels of RS in the latter pastas. Kim et al. [32] also reported that the reduction in cohesiveness between starch and protein could increase the accessibility of starch to alpha amylase resulting in increased digestibility in the pasta passed more than once through the sheeting rollers. The existence of a strong protein starch network in WPC fortified pastas could also be established through SEM studies discussed below. 


\subsection{SEM Studies}

The cooked pasta from control (SPF-RWF blends with $3 \%$ gelatinized cassava starch) presented a smooth outer surface and the starch and protein were not separately visible in the SEM pictures. Small cracks and open areas were visible in the control sweet potato pasta (Figure 1(a)). Starch granules were not visible as they were embedded in a strong protein starch network. Sweet potato pasta fortified with $10 \%$ and $20 \%$ whey protein concentrate (WPC) also exhibited a strong starch protein network formation and the gelatinized starch granules could not be differentiated in the SEM pictures (Figure

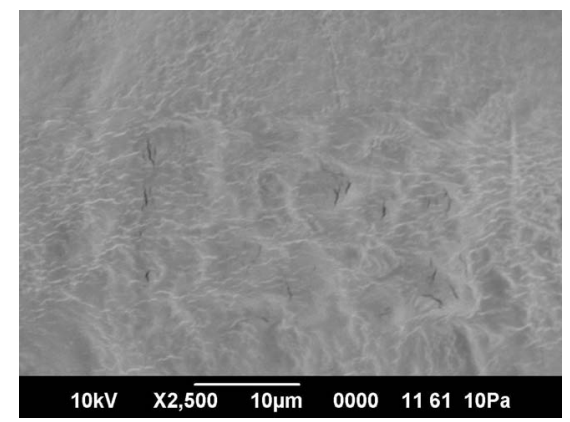

(a)

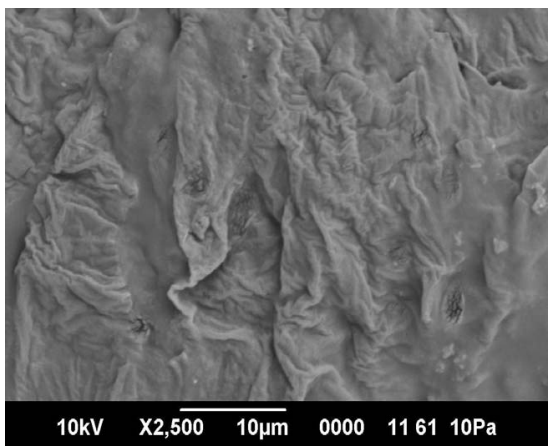

(b)

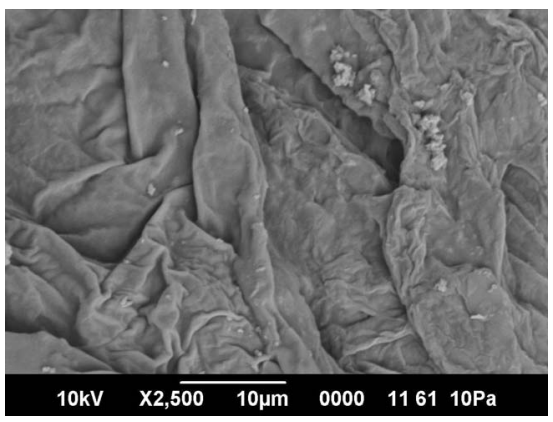

(c)

Figure 1. (a) SEM pictures of control sweet potato pasta (×2500); (b) SEM pictures of $10 \%$ WPC fortified sweet potato pasta $(\times 2500)$; (c) SEM pictures of $20 \%$ WPC fortified sweet potato pasta $(\times 2500)$. 1(b), (c)). Sheet like structures, holding the gelatinized starch inside them were also evident and the thickness of folds was more at 20\% fortification (Figure 1(c)). Fortification of sweet potato pasta with defatted soy flour (DSF) resulted in a slightly loosened network as evidenced from the SEM pictures and fully swollen starch granules as well as gelatinized starch without compact shape were visible and the protein-starch network was also visible on the edges (Figures 2(a), (b)). The loose protein starch network formation in DSF-fortified sweet potato pasta was also supported by the in vitro starch digestibility kinetics, where the time course release of glucose was higher than the $10 \%$ and $20 \%$ WPC pasta (Table 6), indicating the enhanced entry of $\alpha$-amylase into the loose protein-starch network. Fish powder (FP)fortified pasta samples had the least protein-starch network formation as evidenced from the SEM pictures (Figures 3(a), (b)). Starch granules were fully swollen during cooking and had lost their shape. Leaching of amylase would have also resulted in higher cooking loss as well as higher in vitro starch digestibility (Tables 2 and 6 respectively). Exposure of discrete "uncovered" starch granules and discontinuous protein matrix were also reported for pea fiber fortified durum wheat pasta [33]. SEM photographs of protein fortified sweet potato pasta indicate that WPC could mimic gluten in the in-

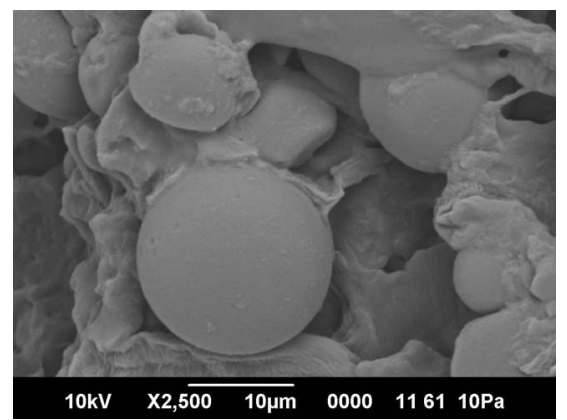

(a)

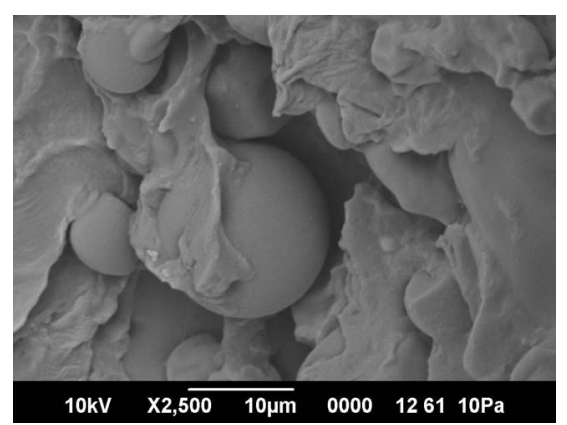

(b)

Figure 2. (a) SEM pictures of $10 \%$ DSF fortified sweet potato pasta $(\times 2500)$; (b) SEM pictures of $20 \%$ DSF fortified sweet potato pasta $(\times 2500)$. 


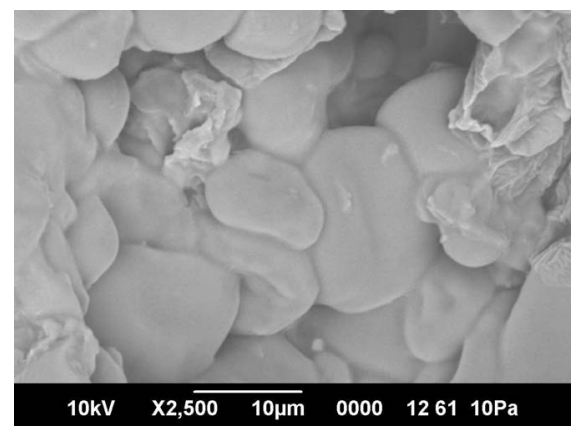

(a)

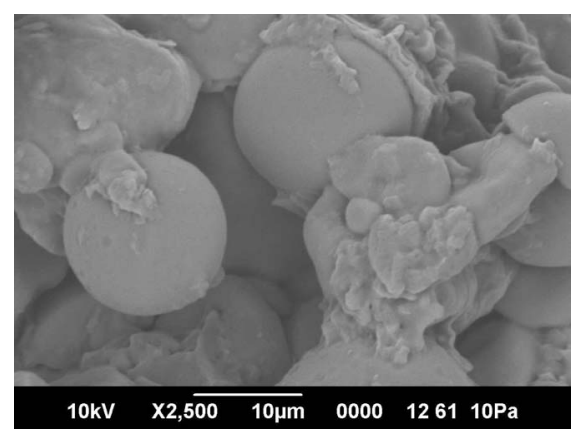

(b)

Figure 3. (a) SEM pictures of $10 \%$ FP fortified sweet potato pasta (×2500); (b) SEM pictures of $20 \%$ FP fortified sweet potato pasta $(\times 2500)$.

formation of a strong starch-protein network.

\section{Conclusions}

High protein pasta, with low starch digestibility was developed from pale cream fleshed sweet potato, using protein sources like whey protein concentrate, defatted soy flour and fish powder. The products exhibited high Swelling Index and significantly high lysine and threonine contents. WPC-fortified sweet potato pasta, which is hitherto unreported, had high values for Essential amino acid index, biological value, nutritional index and protein efficiency ratio. In vitro starch digestibility progressed slowly over a period of $2 \mathrm{~h}$ for all the pastas, with the lowest values for the WPC-fortified pasta. Scanning.

Electron Microscopic studies provided evidence for the formation of strong protein-starch network in WPCfortified sweet potato pasta, while the other two protein sources such as defatted soy flour and fish powder resulted in a loose network leading to higher starch digestibility than WPC pasta. Resistant starch content was the highest for WPC-pasta indicating its potential as a low glycaemic food suited to type 2 diabetic patients, obese patients and weight conscious people.

\section{Acknowledgements}

We acknowledge the support extended by the Sophisti- cated Testing and Instrumentation Center, Cochin University of Science and Technology, Kerala for the Scanning Electron Microscopic studies on pasta and the facilities provided by the Director, CTCRI, India to undertake the work.

\section{REFERENCES}

[1] FAO Statistical Database, "Sweet Potato Production Statistics," 2011

http://faostat.fao.org/site/567/DesktopDefault.aspx?PageI $\mathrm{D}=567$

[2] I. Björck, H. Liljeberg and R. Ostman, "Low Glycaemic Index Foods," British Journal of Nutrition, Vol. 83, Supplement 1, 2000, pp. S149-S155.

[3] H. King, R. E. Aubert and W. H. Herman, "Global Burden of Diabetes 1995-2025: Prevalence, Numerical Estimates and Projection," Diabetes Care, Vol. 21, No. 9, 1998, pp. 1414-1431. doi:10.2337/diacare.21.9.1414

[4] I. Goni and C. Valentin-Gamazo, "Chickpea Flour Ingredient Slows Glycemic Response to Pasta in Healthy Volunteers," Food Chemistry, Vol. 81, No. 4, 2003, pp. 511515. doi:10.1016/S0308-8146(02)00480-6

[5] T. Gelencsér, V. Gal, M. Hodsayi and A. Salgo, "Evaluation of Quality and Digestibility Characteristics of Resistant Starch Enriched Pasta," Food and Bioprocess Technology: An International Journal, Vol. 1, No. 2, 2008, pp. 171-179. doi:10.1007/s11947-007-0040-Z

[6] S. Kusano and H. Abe, "Anti-Diabetic Activity of WhiteSkinned Sweet Potato (Ipomoea batatas L.) in Obese Zucker Fatty Rats," Biology \& Pharmacology Bulletin, Vol. 23, No. 2326, 2000, pp. 23-26.

doi:10.1248/bpb.23.23

[7] M. Petitot, J. Abecassis and V. Micard, "Structuring of Pasta Components during Processing: Impact on Starch and Protein Digestibility and Allergenicity," Trends in Food Science and Technology, Vol. 20, No. 11-12, 2009, pp. 521-532. doi:10.1016/j.tifs.2009.06.005

[8] C. Stephenson, "World's Best Pasta," Macaroni Journal, Vol. 65, 1983, pp. 4-8.

[9] M. A. Sadehi and S. Bhagya, "Quality Characteristics of Pasta Enriched with Mustard Protein Isolate," Journal of Food Science, Vol. 73, No. 5, 2008, pp. S229-S237. doi:10.1111/j.1750-3841.2008.00742.x

[10] M. Petitot, L. Boyer, C. Minier and V. Micard, "Fortification of Pasta with Split Pea and Faba Bean Flours: Pasta Processing and Quality Evaluation," Food Research International, Vol. 43, No. 2, 2010, pp. 634-641. doi:10.1016/j.foodres.2009.07.020

[11] L. S. Collado and H. Corke, "Use of Wheat-Sweet Potato Composite Flour in Yellow-Alkaline and White-Salted Noodles," Cereal Chemistry, Vol. 73, No. 4, 1996, pp. 439-444.

[12] K. Limroongreungrat and Y. W. Huang, "Pasta Products Made from Sweet Potato Fortified with Soy Protein," LWT Food Science \& Technology, Vol. 40, No. 2, 2007, pp. 200-206. 
[13] M. S. Anthony, T. B. Clarkson and J. K. Williams, "Effects of Soy Isoflavones on Atherosclerosis Potential Mechanisms," The American Journal of Clinical Nutrition, Vol. 68, Supplement 6, 1998, pp. S1390-S1393.

[14] M. J. Messina, "Legumes and Soybeans: Overview of Their Nutritional Profiles and Health Effects," American Journal of Clinical Nutrition, Vol. 70, Supplement 3, 1999, pp. S439-S450.

[15] F. A. Manthey, A. R. Yalla, T. J. Dick and M. Badaruddin, "Extrusion Properties and Cooking Quality of Spaghetti Containing Buckwheat Bran Flour," Cereal Chemistry, Vol. 81, No. 2, 2004, pp. 232-236. doi:10.1094/CCHEM.2004.81.2.232

[16] AACC, "Approved Methods of the American Association of Cereal Chemists, (Method 66-50)," 10th Edition, AACC/ Eagan Press, St. Paul, 2000.

[17] C. Mestres, P. Colonna and A. Buleon, "Characteristics of Starch Networks within Rice Flour Noodles and Mungbean Starch Vermicelli," Journal of Food Science, Vol. 53, No. 6, 1988, pp. 1809-1812. doi:10.1111/j.1365-2621.1988.tb07848.x

[18] A. Debbous and C. Doctkott, "Effect of Process Variables on Spaghetti Quality," Cereal Chemistry, Vol. 73, No. 6, 1996, pp. 673-677.

[19] AOAC, "Official Methods of Analysis," 16th Edition, Association of Official Agricultural Chemists, Washington DC, 1995.

[20] B. A. Bidingmeyer, S. A. Cohen, T. L. Tarvin and B. Frost, "A New Rapid Highly Sensitive Analysis of Amino Acids in Food Type Sample," Journal of the Association of Analytical Chemists, Vol. 70, No. 2, 1987, pp. 241261.

[21] P. M. Szakács and I. M. Perl, "Determination of Tryptophan in Unhydrolyzed Food and Feedstuff by the Acid Ninhydrin Method," Journal of Agricultural and Food Chemistry, Vol. 38, No. 3, 1990, pp. 72-726.

[22] FAO, "Amino Acid Content of Foods and Biological Data on Proteins," Food and Agriculture Organization, Rome, 1968.

[23] B. L. Oser, "Methods for Integrating Essential Amino Acid Content in the Nutritional Evaluation of Protein," Journal of American Dietetic Association, Vol. 27, No. 5, 1951, pp. 399-404.

[24] B. L. Oser, "Protein and Amino Acid Nutrition," Academic Press, New York, 1959.

[25] E. V. Crisan and A. Sands, "Nutritional Value of Edible Mushroom," In: S. T. Chang and W. A. Hayer, Eds., Biology and Cultivation of Edible Mushrooms, Academic Press, New York, 1978, pp. 137-168.

[26] L. D. Satterlee, H. F. Marshall and I. M. Tennyson, "Measuring Protein Quality," Journal of the American Oil Chemists Society, Vol. 56, No. 3, 1979, pp. 103-109. doi:10.1007/BF02671431

[27] M. Obulesu and S. Bhagya, "Biochemical, Functional and Nutritional Characteristics of Soy Protein Concentrate Prepared by Thermal Processing," Journal of Food Sci- ence and Technology, Vol. 43, No. 2, 2006, pp. 161-166.

[28] S. Moore and W. H. Stein, "Analysis of Amino Acids," In: S. P. Colowick and N. O. Kaplan, Eds., Methods in Enzymology, Academic Press, New York, 1948, pp. 468471.

[29] S. N. Moorthy and G. Padmaja, "A Rapid Titrimetric Method for the Determination of Starch Content of Cassava Tubers," Journal of Root Crops, Vol. 28, No. 1, 2002, pp. 30-37.

[30] H. N. Englyst, J. Veenstra and G. J. Hudson, "Measurement of Rapidly Available Glucose (RAG) in Plant Foods: A Potential in Vitro Predictor of the Glycaemic Response," British Journal of Nutrition, Vol. 75, No. 3, 1996, pp. 327-337. doi:10.1079/BJN19960137

[31] B. V. McCleary and D. A. Monaghan, "Measurement of Resistant Starch," Journal of the Association of Analytical Chemists, Vol. 85, No. 3, 2002, pp. 665-675.

[32] E. H. J. Kim, J. R. Petrie, L. Motoi, M. P. Morgenstern, K. H. Sulton, S. Mishra and L. D. Simmons, "Effect of Structural and Physico-Chemical Characteristics of the Protein Matrix in Pasta on in Vitro Starch Digestibility," Food Biophysics, Vol. 3, No. 2, 2008, pp. 229-234. doi:10.1007/s11483-008-9066-7

[33] C. M. Tudorică, V. Kuri and C. S. Brennan, "Nutritional and Physicochemical Characteristics of Dietary Fiber Enriched Pasta," Journal of Agricultural and Food Chemistry, Vol. 50, No. 2, 2002, pp. 347-356. doi:10.1021/jf0106953

[34] L. M.Tam, H. Corke, W. T. Tan, J. Li and L. S. Collado, "Production of Bihon-Type Noodles from Maize Starch Differing in Amylose Content," Cereal Chemistry, Vol. 81, No. 4, 2004, pp. 475-480. doi:10.1094/CCHEM.2004.81.4.475

[35] J. Vansteelandt and J. A. Delcour, "Physical Behaviour of Durum Wheat Starch (Triticum durum) during Industrial Pasta Processing," Journal of Agricultural and Food Chemistry, Vol. 46, No. 7, 1998, pp. 2499-2503. doi:10.1021/if9710692

[36] P. Rayas-Duarte, C. M. Mock and L. D. Satterlee, "Quality of Spaghetti Containing Buckwheat, Amaranth and Lupin Flours," Cereal Chemistry, Vol. 73, No. 3, 1996, pp. 381-387.

[37] L. J. Malcolmson, R. R. Matsuo and R. Balshaw, "Textural Optimization of Spaghetti Using Response Surface Methodology: Effects of Drying Temperature and Durum Protein Level," Cereal Chemistry, Vol. 70, No. 4, 1993, pp. 417-423.

[38] FAO/WHO/UNU, "Energy and Protein Requirements," Technical Series 7241, FAO/WHO/UNU Publications, Rome, 1985.

[39] The Real Italian Pasta, "Nutritional Values," 2010. http://www.pasta.go.it/values.htm

[40] S. Sindayikengera and W. S. Xia, "Nutritional Evaluation of Caseins and Whey Proteins and Their Hydrolysates from Protamex," Journal of Zhejiang University SCIENCEB, Vol. 7, No. 2, 2006, pp. 90-98. doi:10.1631/jzus.2006.B0090 
[41] T. Gelencsér, V. Gal and A. Salgo, "Effects of Applied Process on the in Vitro Digestibility and Resistant Starch Content of Pasta Products," Food and Bioprocess Tech- nology: An International Journal, Vol. 3, No. 4, 2010, pp. 491-497. doi:10.1007/s11947-008-0105-7 